\title{
Exploring and evaluating Vertically Integrated Teaching in Ethical Decision-Making (VIT-EDM) in pharmacy
}

\author{
Leen Fino ${ }^{1,2}$ (D), Iman A. Basheti ${ }^{1,2}$ (D) , Bandana Saini ${ }^{1}$ (D), Rebekah Moles ${ }^{1}$ (iD), Betty B. Chaar ${ }^{1}$ iD \\ ${ }^{1}$ Faculty of Medicine and Health, University of Sydney, Sydney, Australia \\ ${ }^{2}$ Faculty of Pharmacy; Applied Science Private University, Jordan
}

\author{
Keywords \\ Education \\ Ethical dilemma \\ Ethics \\ Moral-reasoning \\ PEP \\ Pharmacy Ethics Teaching \\ Correspondence \\ Leen Fino \\ School of Pharmacy \\ Faculty of Medicine and Health \\ University of Sydney \\ Sydney \\ NSW 2006 \\ Australia \\ Ifin4930@uni.sydney.edu.au
}

\begin{abstract}
Background: With increased patient-centred care, pharmacists are often faced with ethical dilemmas and expected to provide solutions for practice dilemmas, relying on ethical judgment, principles of professional ethics, standards of practice, and moral reasoning capabilities. Pharmacists need to be competent in ethical decision-making which will enable them to act in a morally preferable and justifiable manner with patients. Literature has shown that moral reasoning skills are teachable and measurable competencies in healthcare. Objective: To evaluate the impact of implementing a vertically integrated teaching approach in ethical decision-making (VIT-EDM), on moral reasoning capabilities of pharmacy students as they progressed from year-one (pre-exposure to teaching intervention) to final year (postintervention) of pharmacy studies, using the Professional Ethics in Pharmacy test (PEP) as a surrogate measure of moral reasoning capabilities. Methods: Cross-sectional, parallel cohort, comparison study, using PEP. A de-identified electronic survey link was emailed to enrolled students in each targeted cohort. Descriptive and inferential statistics were conducted using SPSS. Results: Fourth-year students' confidence measures were significantly higher in decision-making. Furthermore, students' decisionmaking and moral reasoning measures were higher in fourth-year students. They generally demonstrated moral reasoning capabilities belonging to stage four of moral reasoning levels, which is related to benefitting patients while respecting authorities and legal requirements. However, the difference in the P-scores (fourth-year and first-year) was not found statistically significant. Conclusion: Findings of this study underlined the positive impact of the (VIT-EDM) approach, a relatively novel mixedmethod pedagogy in teaching pharmacy ethics. It highlighted the enhanced confidence of students in ethical decision-making when facing an ethical dilemma.
\end{abstract}

\section{Introduction}

Pharmacists across the world are responsible for medicines supply and their safe and effective use (Tham, 2017). They are often expected to make difficult decisions in practice or help patients make such decisions about their treatment. With increased patient-centred care, pharmacists are often faced with ethical dilemmas and expected to provide solutions for practice dilemmas, relying on ethical judgment, principles of professional ethics, standards of practice, and moral reasoning capabilities (Benson et al., 2009; Chaar, 2009).

Principles of professional ethics in pharmacy are based on moral theory and applied ethics, ethics in healthcare, pharmacists' duties, patients' rights, and legal requirements (Chaar et al., 2005; Tham, 2017).
Pharmacists need to be competent in ethical decisionmaking to enable them to act in a morally preferable and justifiable manner with patients in everyday practice (Kruijtbosch et al., 2019).

Ethical decision-making requires pharmacists to possess high-order moral reasoning capabilities. Moral reasoning, described as a "cognitive decision-making process", inherently implies a person has the ability to perceive and consider competing moral principles and arrive at a reasoned decision that is morally acceptable (DeMella et al., 2017; Schlesselman, 2014). Literature has shown that moral reasoning skills are teachable and measurable competencies in healthcare sciences such as pharmacy and medicine (Self et al., 1993; Latif, 1999; Self et al., 1998; Gallagher, 2011). For example, Self and authors (1998) demonstrated that teaching ethics 
could significantly increase moral reasoning skills using small-group case-study discussions as a method of teaching.

Accrediting bodies regard it crucial that pharmacy students are appropriately trained in professional ethics and ethical decision-making in pharmacy (ACPE, 2016). To reinforce aspects of professionalism and ethical decision-making, both national and international pharmacy bodies such as the Accreditation Council for Pharmacy Education (ACPE) in the United States (USA) (2016) and the Australian Pharmacy Council (APC) (2020) consider the teaching of principles of professional behaviour and competencies in resolving ethical dilemmas essential to the development of pharmacists.

According to Beshara and authors (2019), there is no clear consensus on the ideal pedagogy for teaching and training ethical decision-making skills for pharmacists. This has fostered research exploring effective methods of enhancing ethical decision-making competencies in health professionals. Studies have explored various methods of teaching professional ethics, for example, using workshops (Saw et al., 2018), role-play (Al-Aqeel, 2013) or team-based learning (Hasan, 2015). However, the actual effectiveness of these methods has not been evaluated, as most of these studies relied on interviews or self-assessment questionnaires rather than validated instruments (Rest et al., 1999; Hasan, 2015; Saw et al., 2018).

In the language of cognitive structuralist theories of moral development, such as the Theory of Cognitive Moral Development (Kohlberg \& Goslin, 1969; Rest et al., 1999) (Figure 1), the objective of such ethical training is to facilitate progression to more elevated levels of moral reasoning, e.g. pre-conventional thinking (foundational ego-centric concerns of physical consequences of actions) to post-conventional or principled reasoning (concerned with universal justice/fairness) (Kohlberg \& Goslin, 1969).

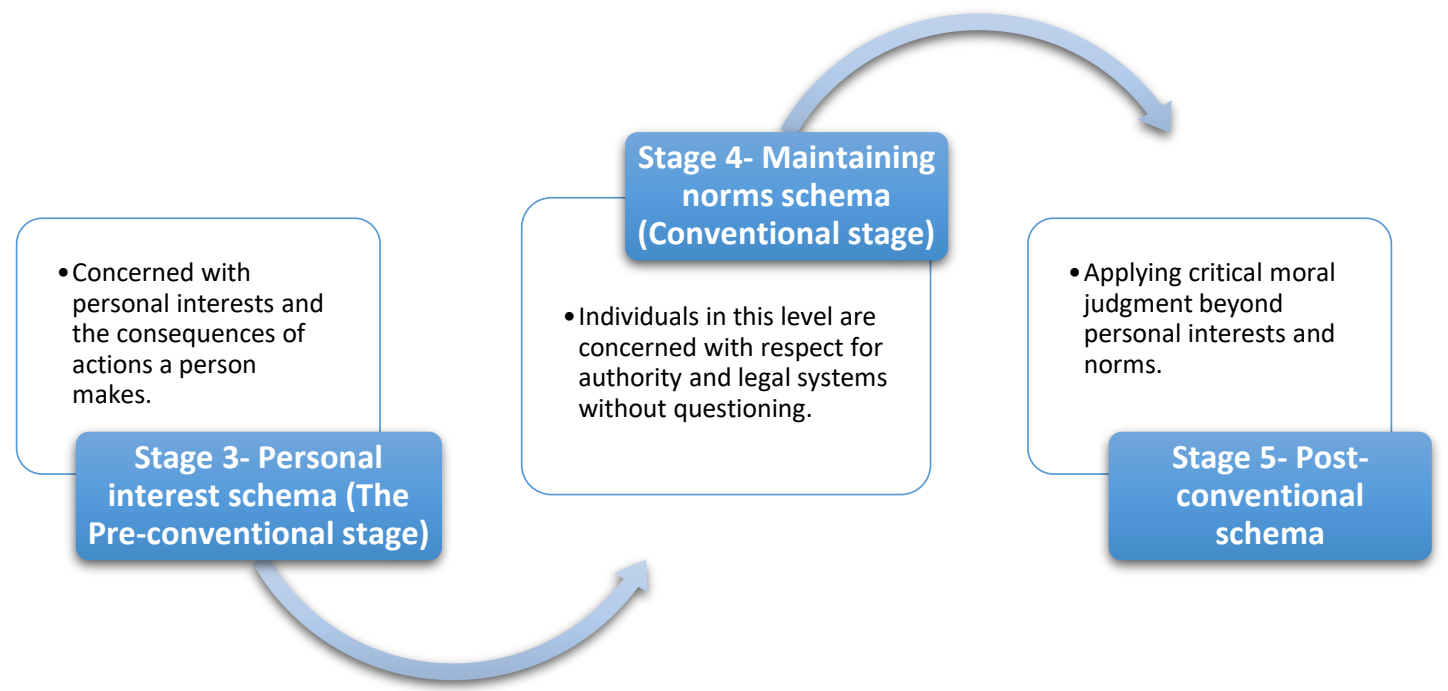

Figure 1: Cognitive Moral Development (CMD) theory and the further established work of Rest and authors (1999)

Evidence supports that the moral reasoning trajectory of students develops through various stages, with time and exposure to a number of elements such as a profession's principles as they pertain to legal, moral, and ethical issues and exposure to the Professional Code of Ethics, which in the case of pharmacy, describes pharmacists' moral/practical responsibilities in practice (Kohlberg \& Goslin, 1969; DeMella et al., 2017). Literature also suggests that pharmacists are often unfamiliar with their national Code of Ethics, relying on personal values and common sense to circumvent ethical dilemmas encountered in practice, rather than referring to their code of ethics (Fino et al., 2020), which emphasises ethical values that support professionalism (PSA, 2017). Sim and authors (2019) also suggested that pharmacists' comprehension of and competence in dealing with ethical dilemmas were strongly affected by personal values, cultural/social norms, and also educational experiences at the university.

At the University of Sydney, a relatively new pedagogical approach to teaching and training ethical competency in pharmacy, which is described by vertically integrating the teaching and training of professional ethics in pharmacy across the curriculum in each of the four years of the Bachelor of Pharmacy (B.Pharm.) course; and called "Vertically Integrated Teaching in Ethical DecisionMaking" (VIT-EDM) (Pearson \& Hubball, 2012). It starts by introducing pharmacy ethics at the beginning of students' undergraduate learning (year-one), building on this introduction throughout their years of training in various forms, e.g. didactic lectures, exploring the many aspects of ethical decision-making in the context of different disease states and patient diversity- mainly in 
case-based story-telling methods, and introducing the Code of Ethics in year-three (PSA, 2017). This approach is then translated into action in the last semester of the students' training in ethical decision-making in the form of 'simulated patient encounter' workshops, allowing students to apply theory to practice.

This study aimed to evaluate the impact of this pedagogical approach on moral reasoning capabilities of pharmacy students as they progressed from year one to their final year in pharmacy studies, using a validated instrument which is the Professional Ethics in Pharmacy test (PEP) (Chaar, 2009) as a surrogate measure of moral reasoning capabilities.

\section{Method}

\section{Study design}

This study was a cross-sectional, parallel cohort, comparison study, using a validated instrument: the Professional Ethics in Pharmacy test (PEP), which is a validated instrument used as a surrogate measure of moral reasoning capabilities (Chaar, 2009), with cohorts from first-year pharmacy students as the "comparison group" (yet to be exposed to this topic teaching approach) and fourth-year pharmacy students at the University of Sydney, Australia (post-exposure and teaching intervention).

\section{Sample and recruitment}

Generic, de-identified invitations were emailed to students at the School of Pharmacy, the University of Sydney enrolled in year four in November 2019, and to those in year one at entry-level in April 2020. Students' emails were obtained from lists of enrolled students in each targeted cohort. The participants' information statement was emailed to students, and along with a link to the electronic survey (the Professional Ethics in Pharmacy test, PEP). Survey submission was regarded as implied consent. Participation in the surveys was voluntary, de-identified, and not linked to any course credit. To maintain student anonymity, no identifiable information was requested in the survey.

\section{Ethics approval}

Ethics approval for the collection and use of data was obtained from the Human Research Ethics Committee (HREC) of the University of Sydney (2019/709).

\section{Assessment instrument}

The survey: Professional Ethics in Pharmacy Test (PEP)

The Professional Ethics in Pharmacy (PEP) test (Chaar, 2009); is a validated instrument used as a surrogate measure of moral reasoning capabilities of pharmacy students and used in this study to evaluate professional ethics teaching methods. The PEP survey is a surrogate measurement of cognitive moral development in the context of professional ethics in pharmacy; it is constituted of three pharmacy-specific scenarios. For any specific professional context, it has been suggested that real-life case studies presenting profession-specific scenarios work better than hypothetical scenarios in terms of understanding moral behaviours (Bebeau et al., 1985). PEP provides a " $p$-score" and other indicators of capabilities (confidence, dilemma resolution, etc.) for each participant, indicating their level of competence in moral reasoning and ethical decision-making (Chaar, 2009).

\section{Analysis}

Descriptive and inferential statistics were conducted using SPSS (IBM SPSS Statistics for Windows version 25). Normality tests were conducted for relevant outcomes of interest. Means and standard deviations were calculated and compared using Independent-Samples ttests and Chi-square tests where appropriate. A $p$-value of less than 0.05 was adopted to represent a significant statistical difference.

First-year students' results were considered to be the study's "comparison group", as the survey was sent to students before pharmacy ethics was taught in the firstyear curriculum. During the scoring process, individual survey responses were subjected to reliability checks to determine outliers, random responses, and "bogus data" (DeSimone et al., 2015). Data were screened for disengaged responses (i.e. "straight liners" and pattern response). These reliability checks also assessed responses for social desirability bias. As per PEP instructions (Chaar, 2009), if a student prioritised a "meaningless item" more than three times in the survey, this would lead to its exclusion.

\section{Results}

A total of 469 pharmacy students were invited to participate in this study. A total of 128 students completed the full PEP survey (Table I). A total of six responses failed the reliability check, resulting in their exclusion.

Table I: Participating students

\begin{tabular}{lcccc}
\hline Cohort & $\begin{array}{c}\text { Number } \\
\text { of } \\
\text { students } \\
\text { in each } \\
\text { cohort }\end{array}$ & $\begin{array}{c}\text { Number of } \\
\text { students } \\
\text { fully } \\
\text { responded }\end{array}$ & $\begin{array}{c}\text { Number of } \\
\text { students } \\
\text { partially } \\
\text { responded }\end{array}$ & $\begin{array}{c}\text { Response } \\
\text { Rate }\end{array}$ \\
\hline $\begin{array}{l}\text { First } \\
\text { year }\end{array}$ & 300 & 63 & 5 & $21 \%$ \\
\hline $\begin{array}{l}\text { Fourth } \\
\text { year }\end{array}$ & 169 & 59 & 1 & $35 \%$ \\
\hline
\end{tabular}




\section{Overview}

First-year pharmacy students' response rate was 21\%, and fourth-year pharmacy students' response rate was 35\%. Fourth-year students' confidence measures were significantly higher in decision-making, which was statistically significant in regards to a genuine request for a scheduled medication without providing a valid prescription, illustrated in dilemma-2 (Table II) $(p<0.05)$.

Furthermore, students' decision-making and moral reasoning measures were higher in fourth-year students, most prominently in dilemma-1 (Table II), which was about providing an (OTC) product of questionable benefit. Fourth-year students generally demonstrated moral reasoning capabilities belonging to stage four of cognitive moral development levels, which is related to benefitting patients while respecting authorities and legal requirements. Also, the fourth-year cohort demonstrated higher awareness of legal obligations, which was expected of them after their training in legal requirements of the profession.

\section{Table II: Summary of PEP dilemmas}

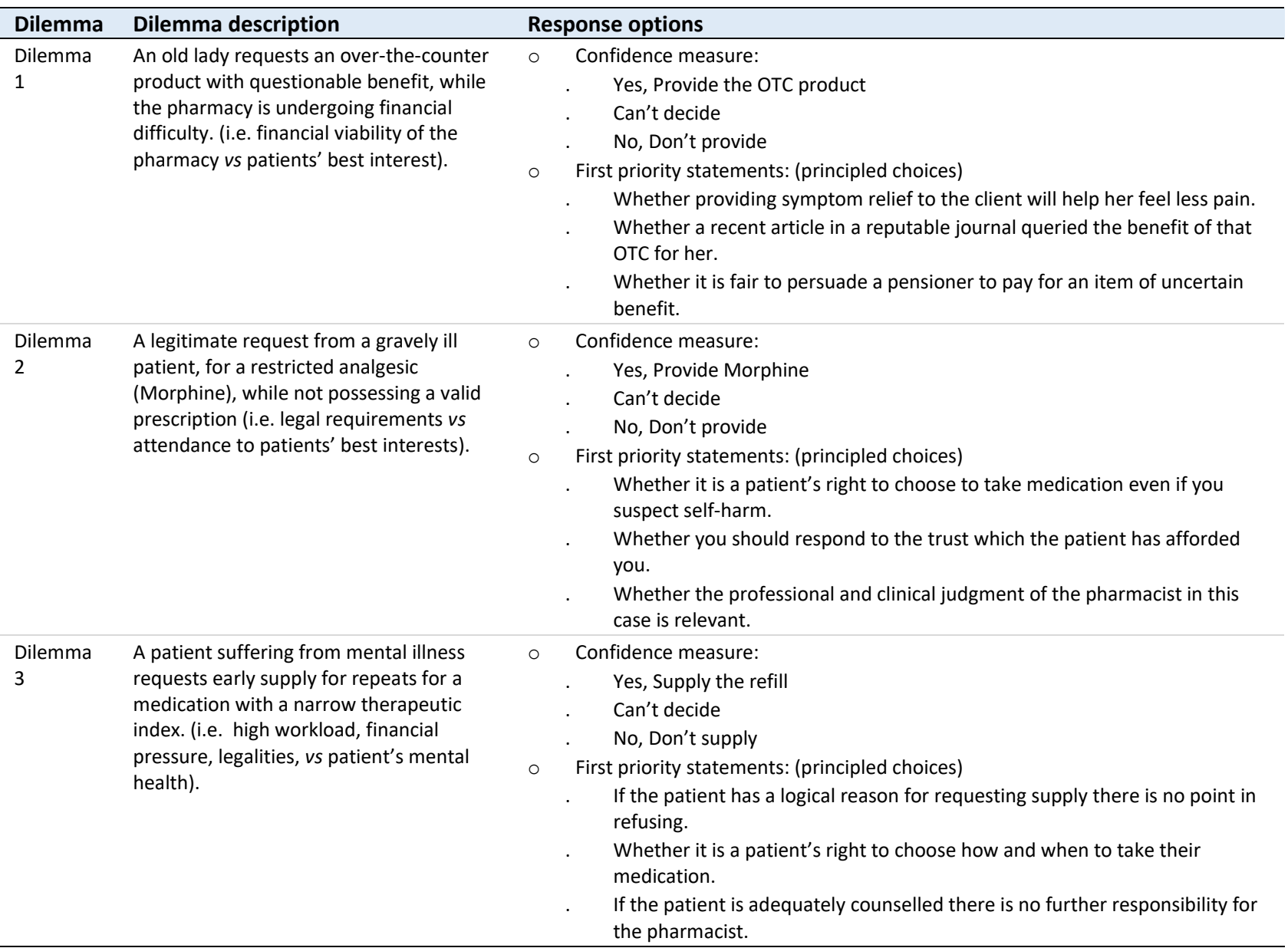

\section{P-score results}

The upward trend of students' $p$-scores was considered an indication of a positive impact of the pedagogy applied. First-year students' $p$-score (predelivery of teaching approach) average was 23.3; which increased to $\mathbf{2 4 . 2}$ for fourth-year students after the delivery of this teaching method, representing a $p$-score increase of $0.9(95 \% \mathrm{Cl},-4.165$ to 2.521 ; $p=0.590)$. Despite the difference in the $p$-scores (fourth-year and first-year), not statistically significant, this upward trend of the $p$-score was indicative of a constructive influence of VIT-EDM, as the $p$-score only measures change(s) to the fifth stage of moral reasoning and does not focus on the upward changes from lower stages such as stage-three to stage-four of moral reasoning which was the case in this study.

\section{Confidence in decision-making}

As mentioned above, findings indicated enhanced levels of confidence in fourth-year students' decision- 
making compared to first-year students and this difference was statistically significant $(p<0.05)$. This was particularly noticeable in dilemma-2 (Table II), depicting a legitimate request from a seriously ill patient for a restricted analgesic (Morphine), without a valid prescription. Only $15 \%$ of fourth-year students were indecisive (i.e. chose the "Can't decide" option), compared to $29.4 \%$ of first-year students. This also illustrated a positive impact of the pedagogical approach adopted in training students.

\section{Moral development - transitions to a higher schema of moral reasoning capabilities}

The development of students' moral reasoning skills can be observed in Figure 2. This illustrated the ascent of students' moral reasoning capability scores towards the post-conventional stage (stage-five) and highest stage of cognitive moral development. In dilemma-1, $50 \%$ of fourth-year students prioritised a stage-five (post-conventional) choice in their decision-making on supplying a product with doubtful benefits for an elderly patient, compared to $30.8 \%$ of the first-year cohort.

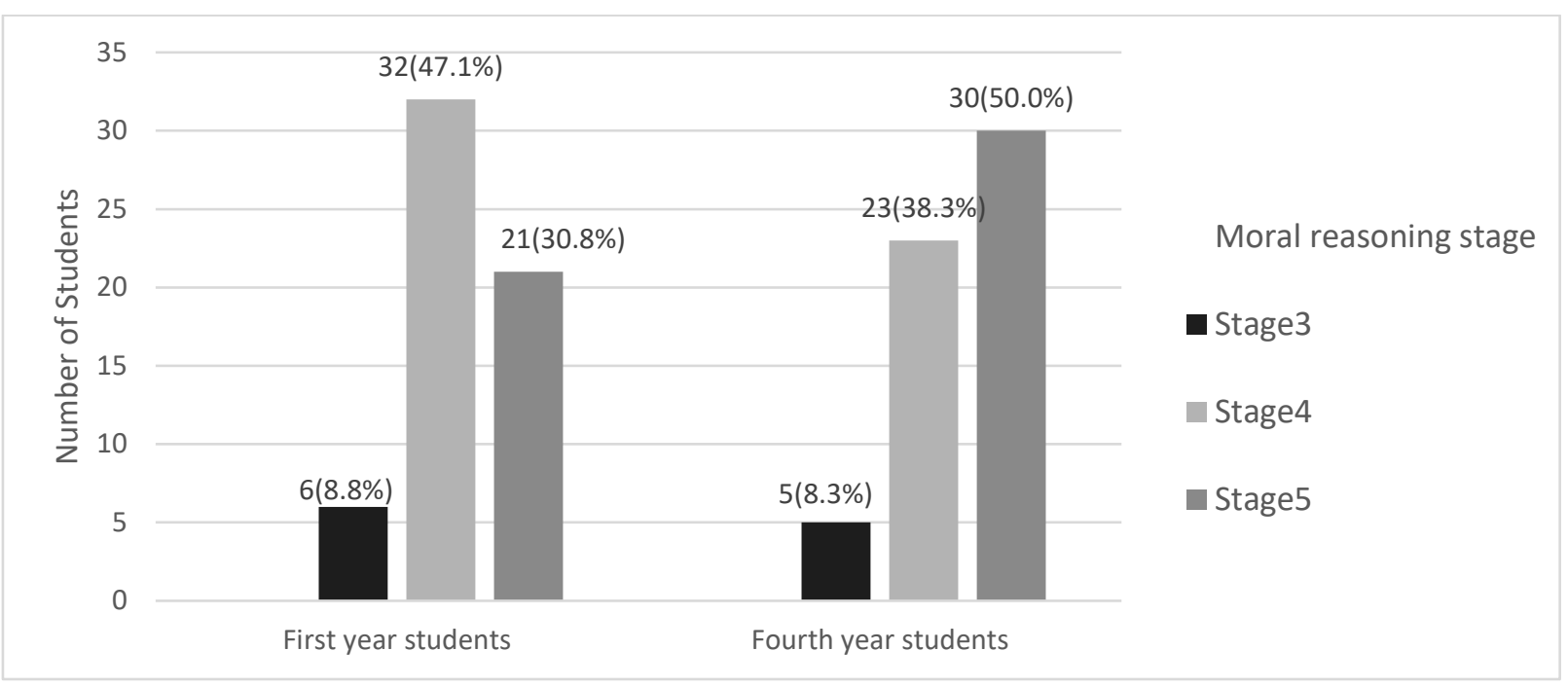

Figure 2: Moral development-dilemma 1

\section{Legal awareness}

Data also indicated that students became more aware of legal ramifications of their decisions as they progressed in their studies. This was well-illustrated in dilemma-2, (Table II), as $78.3 \%$ of the fourth-year students decided against providing the controlled drug to the patient, compared to $48.5 \%$ of the first-year students.

Additionally, fourth-year participants tended to prioritise choices more in adherence with legal regulations (Figure 3), adopting more legal-driven practices (stage-four moral reasoning) $(p<0.05)$.

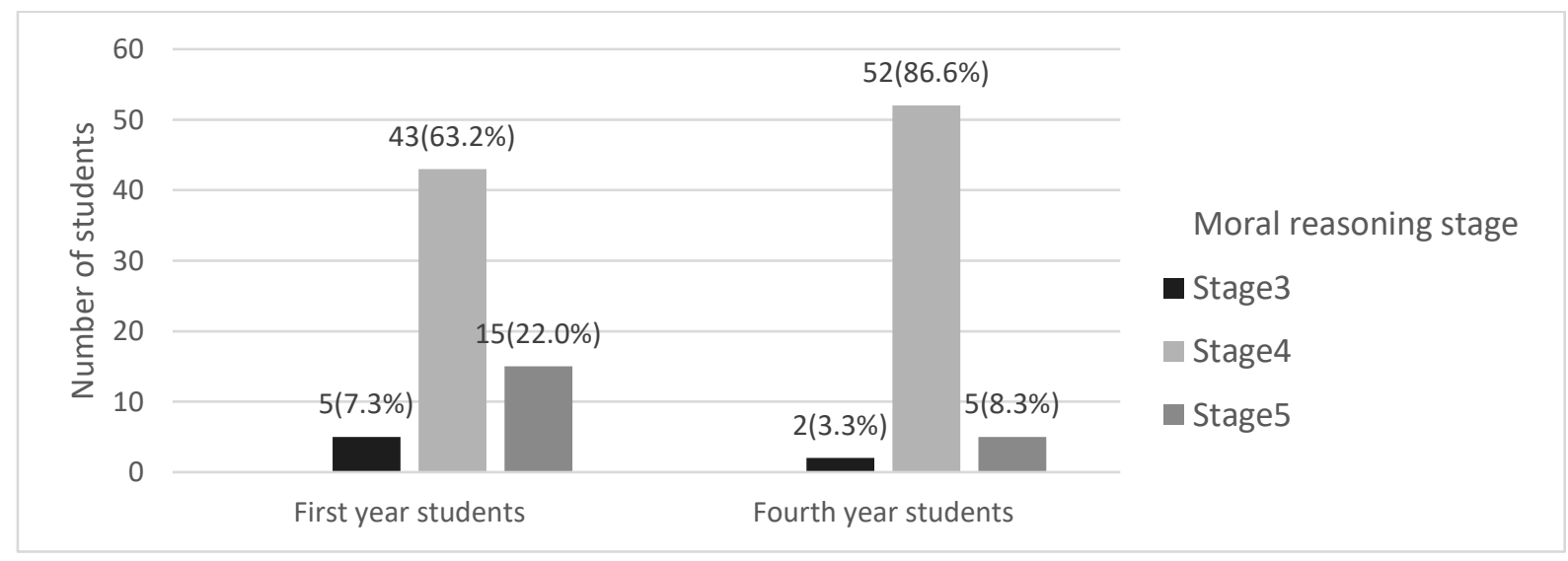

Figure 3: Legal awareness-dilemma 2 


\section{Financial pressure}

In responding to dilemma-3 (Table II), which described a case of high workload, financial pressure, legalities, and a patient's mental health, $40 \%$ of the fourth-year cohort prioritised business-oriented choices by providing the patient with the medicines requested (stage-three). On the other hand, only $27.9 \%$ of the first-year cohort selected business-oriented choices. This might be attributed to the complexity of this scenario with overlapping challenges.

This was also noticeable in dilemma-1 (Table II), as a higher per cent of fourth-year pharmacy students (15\%), decided to supply a product with questionable benefits for an elderly patient, compared to $8.8 \%$ of first-year students $(p<0.05)$.

\section{Discussion}

This study explored the impact of a relatively new pedagogical approach to teaching pharmacy ethics, the Vertically Integrated Teaching in Ethical DecisionMaking "VIT-EDM". This approach aimed to nurture cognitive moral development in the context of a healthcare profession such as pharmacy, to enable students to understand their professional responsibilities better and manage decision-making in a dynamic environment similar to the environment they will encounter in a pharmacy setting (Al-Aqeel, 2013). Findings indicated general enhancement of cognitive moral development and confidence in ethical decision-making, as well as improved legal knowledge and processing.

This educational approach was incrementally distributed across the curriculum in each of the four years of undergraduate pharmacy studies. The socalled "vertical" framework builds students' competencies in ethical decision-making by firstly introducing them to professional ethics in a theoretical approach, i.e. didactic lectures in year one up to year three, using cases to illustrate ethical dilemmas and how to apply decision-making steps to resolve the dilemma. These lectures equipped students with knowledge about fundamental concepts in moral philosophy, bioethics, decision-making, and a focus on their Code of Ethics. Students in fourth-year B.Pharm. are exposed to simulated patient role-play in workshops designed to foster discussion, reflection, and deliberation.

Evidence from the literature demonstrated improvement in professional awareness and professional characteristics by teaching pharmacy ethics using pedagogies such as case-based workshops (Saw et al., 2018), role-play (Al-Aqeel, 2013), teambased learning activities (Hasan, 2015) and non- traditional approaches, e.g. games and reflective drawings (Wilby \& Nasr, 2016). The VIT-EDM is a combination of some of these approaches, designed with the intent to build competencies rather than expose the student to theoretical concepts and notions of social norms in the profession without training in generic skills in ethical decision-making.

This study was instigated after a study conducted in Australia and New Zealand had identified a general lack of scaffolding and pedagogical rationale for pharmacy ethics courses and highlighted the need for well-designed, stand-alone courses with defined pedagogy and content (Beshara et al., 2019). Other past studies that tried to evaluate the impact of educational interventions in the domain of professional ethics in pharmacy, have often relied on the use of non-validated instruments, such as improvised pre-and post-surveys, or self-reported opinion discussions with students (Horton et al., 2014; Hasan, 2015), which according to Austin and Gregory (2007) tend to yield overestimated results. Al-Aqeel (2013), for example, evaluated the efficacy of their implementation of role-playing in teaching pharmacy law and ethics to pharmacy students by requesting self-reported student feedback in the form of a postcourse qualitative survey. Other studies used a validated instrument that focused only on measuring general moral reasoning capabilities (as opposed to specifically "professional") (DeMella et al., 2017), and qualitative study designs that are not generalisable (Fejzic \& Barker, 2015).

This study, on the other hand, utilised the validated PEP-test instrument to evaluate moral reasoning capabilities in as unbiased a manner possible (Chaar, 2009). The surrogate measure of cognitive moral development, the " $p$-score" taken before and after the VIT-EDM was implemented, using a comparative crosssectional design - testing before any training took place in first-year and just before graduation at the end of fourth-year, explored change in moral reasoning capabilities and the direction the change was trending. This study also compared these parallel cohorts' confidence levels in ethical decision-making competency. The findings indicated significantly higher confidence measures in decision-making and moral reasoning competencies in the fourth-year cohort. As a result of the teaching approach, students became more confident, most prominently in dilemmas involving legal issues, as their moral reasoning shifted towards the conventional schema (stage-four moral reasoning) in which individuals are concerned with respecting authorities and legal systems.

The study highlighted changes in the students' $p$ scores, trending upwards as the curriculum progressed. Fourth-year students' responses 
demonstrated an improved understanding of pharmacists' responsibilities and increased confidence in the ability to make ethical decisions. This, too, can be attributed to the pedagogy of the VIT-EDM.

Fejzic and Barker (2015) implemented simulated learning workshops focused on pharmacy practice in their study. Based on qualitative feedback and ad-hoc questionnaires, authors reported the impact of their course as "overwhelmingly positive" and noted improvements in students' pharmacy practice, professionalism, and commitment to professional ethics (Fejzic \& Barker, 2015). Although not a highly dependable source of confirmation of findings, this study highlighted students' perspectives and indicated a positive response to one component of the VIT-EDM method of teaching.

Encouragingly, the majority of the fourth-year students, unlike their first-year counterparts (comparison group), decided against providing a scheduled drug of addiction without a valid prescription. This indicated a shift from stage-three to stage-four moral reasoning levels, which can be attributed to the fact that students had developed higher-order moral reasoning skills and typically became more familiar with forensics and legal requirements of the profession as they progressed in their academic degree. Past studies have demonstrated that licensed pharmacists generally demonstrate characteristics of stage-three moral reasoning because their comprehension and competence in dealing with ethical dilemmas were highly affected by personal values, cultural and social norms (Fino et al., 2020). This shift in stages of moral reasoning development is of significance to the teaching of professional ethics and can be considered an indication of quality pedagogy.

Interestingly, students' responses to dilemma-1 in the first-year cohort were better than those in the fourth year. These business-oriented choices may be ascribed to the fact that fourth-year students had studied a Pharmacy Business Management course, which focused on accounting and financial management, human resource management and marketing in the context of community and/or hospital pharmacy basically emphasising the importance of maintaining the viability of the business side of community pharmacy. Financial pressure, typical of the realm of the business of pharmacy, has often been acknowledged as having a negative impact in undermining and preventing pharmacists from applying ethical principles in decision-making in practice (Chaar et al., 2005; Al-Aqeel, 2013; Mikhael \& Al-Tukmagi, 2016; Arslan et al., 2018; Rajiah \& Venaktaraman, 2019; Fino et al., 2020). The findings were similar to those of Saw and authors (2018), who noted the negative effect financial burdens have on ethical decision-making processes of not only established pharmacists but younger pharmacists in particular. This highlighted the importance of increasing pharmacists' awareness of and resilience to financial pressure in the context of pharmacy practice in the teaching of ethics in pharmacy in the future.

Therefore, whilst this study has underlined the positive impact of VIT-EDM as a relatively new method of teaching, it also indicated the necessity for more training in balancing financial pressure/ business viability for pharmacy students.

\section{Limitations}

This study has demonstrated the positive impact of VIT-EDM; however, the low response rate on the optional survey was a limitation of this study. The generalisability of the survey findings may therefore have been impacted by non-response bias. Moreover, the fourth year cohort could be considered more mature, in particular after exposure to the pharmacy programme in its entirety which might also have positively influenced students' decision-making. . A longitudinal design may strengthen future studies, which might also improve the generalisability of results, as this study's participants were from different cohorts. A mixed-method approach including qualitative interviews with students after taking the survey may also further the understanding of the rationale behind the decision-making of students at different stages within their curriculum. This was not possible in this study, as there was an ethical approval to collect anonymised data only. A follow-up survey targeting students-post-registration to examine changes in their moral-reasoning skills might be of value.

\section{Conclusion}

The findings of this study highlighted the general positive impact of the VIT-EDM approach, a relatively novel mixed-method pedagogy in teaching pharmacy ethics. It demonstrated enhanced confidence of students in ethical decision-making when facing an ethical dilemma, with a positive shift in cognitive moral development and the noticeable increase in awareness of legal obligations required of pharmacists. This study also highlighted the importance of incorporating a deeper and more rigorous effort in teaching resilience to pharmacists prone to financial burdens, which can affect younger pharmacists' ethical decision-making. 


\section{References}

ACPE. (2016). Accreditation Standards and Key Elements for the Professional Programme in Pharmacy Leading to the Doctor of Pharmacy Degree: The Accreditation Council for Pharmacy Education. Standards 2016. Available at: https://www.acpeaccredit.org/pdf/Standards2016FINAL.pdf

Al-Aqeel, S.A. (2013). Pharmacy Students Feedback on the use of Role-play in Teaching Ethics. Pharmacy Education, 13

APC. (2020). Accreditation Standards for Pharmacy Programmes in Australia and New Zealand 2020: Australian Pharmacy Council

Available at

https://www.pharmacycouncil.org.au/standards/

Arslan, M., Tarhan, N., Kalender, S., \& ŞAr, S. (2018). Investigation of factors affecting ethical decision-making process of community pharmacists in professional life. Journal of Research in Pharmacy, 23, 140-145.

https://doi.org/10.12991/jrp.2018.118

Austin, Z., \& Gregory, P.A. (2007). Evaluating the accuracy of pharmacy students' self-assessment skills. American journal of pharmaceutical education, 71(5)

Bebeau, M.J., Rest, J.R., \& Yamoor, C.M. (1985). Measuring dental students' ethical sensitivity. Journal of Dental Education, 49(4), 225-235

Benson, A., Cribb, A., \& Barber, N. (2009). Understanding pharmacists' values: A qualitative study of ideals and dilemmas in UK pharmacy practice. Social Science \& Medicine, 68(12), 2223-2230.

https://doi.org/10.1016/j.socscimed.2009.03.012

Beshara, S., Herron, D., Moles, R.J., \& Chaar, B. (2020). Status of Pharmacy Ethics Education in Australia and New Zealand. American Journal of Pharmaceutical Education, 84(3). https://doi.org/10.5688/ajpe7452

Chaar, B., Brien, J.A., \& Krass, I. (2005). Professional ethics in pharmacy: The Australian experience. International Journal of Pharmacy Practice, 13(3), 195-204.

https://doi.org/10.1211/ijpp.13.3.0005

Chaar, B.B. (2009). Professional ethics in pharmacy practice: Developing a psychometric measure of moral reasoning. Pharmacy World and Science, 31(4), 439-449. https://doi.org/10.1007/s11096-009-9292-1

DeMella, C., Donohoe, K., Morgan, L., Phipps, L., Drisaldi, A., \& Forder, M. (2017). Implementation of an online ethics course into a pharmacy curriculum. Currents in Pharmacy Teaching and Learning, 9(5), 835-840. https://doi.org/10.1016/j.cptl.2017.05.001

DeSimone, J.A., Harms, P.D., \& DeSimone, A.J. (2015). Best practice recommendations for data screening. Journal of Organizational Behavior, 36(2), 171-181.

https://doi.org/10.1002/job.1962

Fejzic, J., \& Barker, M. (2015). Implementing simulated learning modules to improve students' pharmacy practice skills and professionalism. Pharmacy Practice, 13(3). https://10.18549/PharmPract.2015.03.583
Fino, L.B., Basheti, I.A., \& Chaar, B.B. (2020). Exploring Ethical Pharmacy Practice in Jordan. Science and Engineering Ethics. https://10.1007/s11948-020-00231-3

Fino, L.B., Basheti, I.A., Saini, B., Moles, R., \& Chaar, B.B. (2020). Exploring pharmacy ethics in developing countries: a scoping review. International Journal of Clinical Pharmacy, 42(2), 418-435. https://doi.org/10.1007/s11096-020-010214

Gallagher, C.T. (2011). Building on Bloom: A paradigm for teaching pharmacy law and ethics from the UK. Currents in Pharmacy Teaching and Learning, 3(1), 71-76. https://10.1016/j.cptl.2010.10.002

Hasan, S. (2015). Teaching ethics to pharmacy students using a team-based learning approach. Pharmacy Education, 11

Horton, E.R., Morin, A., Pervanas, H.C., Mukherjee, S.M., \& Belliveau, P. (2014). A Novel Structured Format for Engaging Pharmacy Students in Bioethics Discussions. American Journal of Pharmaceutical Education, 78(9), 171. https://doi.org/10.5688/ajpe789171

Kohlberg, L., \& Goslin, D.A. (1969). Handbook of socialisation theory and research

Kruijtbosch, M., Göttgens-Jansen, W., Floor-Schreudering, A., van Leeuwen, E., \& Bouvy, M.L. (2019). Moral reasoning among Dutch community pharmacists: testing the applicability of the Australian Professional Ethics in Pharmacy test. International journal of clinical pharmacy, 41(5), 1323. https://doi.org/10.1007/s11096-019-00869-5

Latif, D.A. (1999). Using Ethical Dilemma Case Studies to Develop Pharmacy Students' Moral Reasoning. Journal of Pharmacy Teaching, 7(2), 51-66. https://doi.org/10.1300/J060v07n02_06

Mikhael, E.M., \& Al-Tukmagi, H.F. (2016). The compliance of iraqi pharmacists with ethical principles in applying the pharmaceutical care for diabetic patients. Clinical Ethics, 11(4), 159-165. doi:10.1177/1477750916657659

Pearson, M. L., \& Hubball, H. T. (2012). Curricular integration in pharmacy education. American journal of pharmaceutical education, 76(10), 204-204. httpa://doi.org/10.5688/ajpe7610204

PSA. (2017). Code of Ethics for Pharmacists (2017) Pharmaceutical Society of Australia. Available at https://www.psa.org.au/wp-content/uploads/2018/07/PSACode-of-Ethics-2017.pdf

Rajiah, K., \& Venaktaraman, R. (2019). The effect of demographic and social factors on the decision-making of community pharmacists in ethical dilemmas. Journal of Research in Pharmacy Practice, 8(3), 174-177. https://doi.org/10.4103/jrpp.JRPP_19_15

Rest, J., Narvaez, D., Bebeau, M., \& Thoma, S. (1999). A NeoKohlbergian Approach: The DIT and Schema Theory. Educational Psychology Review, 11(4), 291-324. httpa://doi.org/10.1023/A:1022053215271

Rest, J.R., Narvaez, D., Thoma, S.J., \& Bebeau, M.J. (1999) DIT2: Devising and testing a revised instrument of moral judgment. Journal of Educational Psychology, 91(4), 644659. https://doi.org/10.1037/0022-0663.91.4.644 
Saw, P.S., Chuah, L.H., \& Lee, S.W.H. (2018). A practical approach toward teaching ethics to community pharmacists. International Journal of Clinical Pharmacy, 40(5), 1131-1136. https://10.1007/s11096-018-0707-8

Schlesselman, L.S. (2014). A cross-sectional study of applied bioethical reasoning in pharmacy students and preceptors. Pharmacy practice, 12(2), 401-401

Self, J.D., Baldwin, C.D., \& Olivarez, C.M. (1993). Teaching medical ethics to first-year students by using film discussion to develop their moral reasoning. Academic Medicine, 68(5), 383-385. https://doi.org/10.1097/00001888-19930500000025

Self, J.D., Olivarez, C.M., \& Baldwin, C.D. (1998). The amount of small-group case-study discussion needed to improve moral reasoning skills of medical students. Academic Medicine, 73(5), 521-523.

https://doi.org/10.1097/00001888-199805000-00019

Sim, T.F., Sunderland, B., \& Hattingh, H.L. (2019). Exploring influences on pharmacists' and students' ethical reasoning in a changing practice landscape in Australia. International Journal of Clinical Pharmacy, 41(1), 280-288.

https://doi.org/10.1007/s11096-018-0774-x

Tham, J. (2017). Applied Ethics. In H. ten Have (Ed.), Encyclopedia of Global Bioethics (pp. 1-12). Cham: Springer International Publishing

Wilby, K.J., \& Nasr, Z.G. (2016). Bridging theory and practice: Mixed methods approach to instruction of law and ethics within the pharmaceutical sciences. Saudi Pharmaceutical Journal, 24(6), 669-673.

https://doi.org/10.1016/j.jsps.2015.06.001 